\title{
Obesity and dyslipidemia: risk factors for development of senile cataract
}

\author{
Sabrina Fahmida Azim, Qazi Shamima Akhter, Taslima Akter, Fouzia Farid
}

\begin{abstract}
Background: Cataract is a major cause of blindness and visual impairment worldwide.Obesity and dyslipidemia may act as risk factors for development and progression of senile cataract. Objective: To determine obesity and dyslipidemia as the risk factors for development of senile cataract. Methods: This case control study was conducted in the Department of Physiology, Dhaka Medical College, Dhaka from July 2014 to June 2015. For this study, 100 diagnosed senile cataract patients (DSC) of both sexes, aged 41-70 years, were selected by purposive sampling as study group from Department of Ophthalmology, Dhaka Medical College and one hundred noncataract healthy adult subjects (NCG) were recruited as control among the relatives and hospital staff through personal contact. The criteria for inclusions are BMI e" $25.0 \mathrm{~kg} / \mathrm{m}^{2}$, waist circumstances $>88 \mathrm{~cm}$ in female and $>102 \mathrm{~cm}$ in male and waist hip circumference ratio $\mathrm{W}: \mathrm{H}>0.85$ infemale and $>$ in male 0.9 .Person with cataract due to trauma, acute or chronic diarrhoea, kidney disease, history of taking calcium channel blockers, lipid lowering agents and steroid were excluded from this study. For assessing lipid profile TC, TAG, HDLC, LDL-C of all subjects were estimated by enzymatic method. For statistical analyses, unpaired Student's ' $t$ ' test, and logistic regression were done to evaluate the risk factors. Odds ratios (OR) with 95\% Confidence Intervals (CI) were provided. .Results: In this study BMI, WC, W: H, TC, TAG, LDL$\mathrm{C}$ levels were significantly higher $(\mathrm{P}<0.001)$ and HDL-C level was significantly lower $(\mathrm{P}<0.001)$ in diagnosed senile cataract patients(DSC) as compared to non-cataract group(NCG). Conclusion: From the study results, it is concluded that obesity (higher BMI, WC,W: H) and dyslipidemia may act as risk factors for development of senile cataract.
\end{abstract}

Keywords: Obesity, dyslipidemia, cataract, blindness, body mass index, waist circumference, waist hip circumference ratio, lipid profile.

\footnotetext{
J Bangladesh Soc Physiol. 2018, June; 13(1): 29-34 For Authors Affiliation, see end of text.

http://www.banglajol.info/index.php/JBSP DOI: http://dx.doi.org/10.3329/jbsp.v13i1.37846
}

\section{Introduction}

A

ny opacity in the crystalline lens or its capsule, whether developmental or acquired is known as cataract. The disease, which initially prevents clear vision and eventually progress to blindness if left untreated ${ }^{1}$.

Received 10 Feb. 2018; $\quad$ Accepted 19 May 2018

J Bangladesh Soc Physiol. 2018, June; 13(1): 29-34
Senile cataract is a major global health problem because its prevalence is rapidly increasing worldwide as well as in Bangladesh. The World Health Organization estimates that nearly 20 million people are bilaterally blind from cataract ${ }^{2}$. In south-east Asia, cataract is responsible for $50-80 \%$ of all blindness ${ }^{3}$. In Bangladesh, the prevalence of cataract is about $79.6 \%{ }^{4}$. 
The development of cataract is a complex, multifactorial process and several factors such as genes, gender, diabetes, geographic location, UV light exposure, occupational status and nutritional factors in the daily diet have been found to be associated with cataract formation ${ }^{5}$.

In public health perspective, risk factors for senile cataract are readily classified as unmodifiable and potentially modified ${ }^{6}$. Studies suggested that identification and awareness of risk factors for senile cataract could have an important benefit by reducing patient's dependence on the family and society. Identification of risk factors for development of senile cataract and prevention of them may also delay the incidence ${ }^{5}$.

Obesity is defined as abnormal or excessive fat accumulation that may impair health. The most widely used method to assess obesity is the body mass index(BMI), which is equal to weight/ height ${ }^{2}\left(\mathrm{~kg} / \mathrm{m}^{2}\right)$ and a BMI e" $30 \mathrm{~kg} / \mathrm{m}^{2}$ is consideredas obese $\mathrm{WHO}^{7}$. In Asian population the co-morbidities of obesity occur at a lower BMI than in other ethnic groups of the world ${ }^{8}$.

Obesity has been proposed to be a risk factor for cataract development ${ }^{9}$.Some studies was done to observe the relation of cataract with obesity.A population based cross-sectional epidemiologic study was done to observe the association of obesity with cataract andthey found that obesity was significantly associated with senile cataract $^{10 .}$

Senile cataract formation may be associated with some lipid changes in human lens fibers, especially with increased accumulation and redistribution of cholesterol inside these cells. Some evidences suggested an involvement of cholesterol oxide derivatives (oxysterols) in the development of cataract ${ }^{11}$.

A study was done among the women with senile cataract where the researchers found a positive association between high triacylglyceride (TAG) levels and any subtype of senile cataract ${ }^{12}$. Some researchers reported that both low HDL and high TG levels were associated with senile cataract in $\mathrm{USA}^{13}$. Some other researchers suggested that an association existed between the high LDL \& low HDL with the development of lens opacity in both sexes ${ }^{14}$.

But another researcher did not find any significant association between high-TG orlowHDL with senile cataract ${ }^{15}$. The reports of association of dyslipidaemia with development cataract is conflicting. Therefore, the present study has been designed for identification of obesity and dyslipidemia as the risk factors for development of senile cataract.

\section{Methods}

This case control study was conducted in the Department of Physiology, Dhaka Medical College, Dhaka from July 2014 to June 2015. Protocol of this study was approved by Ethical Review Committee of Dhaka Medical College, Dhaka. For this study, 100 diagnosed cataract patients (DSC) of both sexes, aged 41-70 years, were selected by purposive sampling as study group from the Department of Ophthalmology, Dhaka Medical College. One hundred non cataract healthy adult subjects (NCG) were recruited as control among the relatives and hospital staff through personal contact. The criteria for inclusions are BMI $\geq 25.0 \mathrm{~kg} / \mathrm{m}^{216-17}$. Waist circumstances $>88 \mathrm{~cm}$ in female and $>102$ $\mathrm{cm}$ in male and waist hip circumference ratio $\mathrm{W}$ : $\mathrm{H}>0.85$ in female and $>$ in male 0.9 for obesity ${ }^{18-}$ ${ }^{19}$. Person with cataract due to trauma, acute or chronic diarrhoea, kidney disease, history of taking calcium channel blockers, lipid lowering agents and steroid were excluded from this study. After selection of the subjects, the objectives, the nature, purpose and potential risks of all procedures used for the study were explained to each subject in details. Subsequently a detailed family and medical history were taken to rule out any chronic and known illness which runs in the family and also physical activity status were recorded. Anthropometric measurement of the subjects was done and blood pressure was measured. All the information were recorded in a prefixed questionnaire. They were advised to have normal diet, avoid heavy meal and to do normal physical activities for 3 days. Then they were requested to come after 3 days at morning 
in the Department of Physiology, Dhaka Medical College, between 8.00 AM to 9AM, following an overnight (8-14 hours) fasting. With aseptic precaution, $5 \mathrm{ml}$ of venous blood was collected from ante-cubital vein from all subjects. To assess lipid profile, serum TC, TAG HDL-C, LDL-C of all subjects were estimated by enzymatic method in the laboratory of Department of Pathology, Dhaka Medical College, Dhaka.

For Statistical analysis, unpaired Student's ' $\mathrm{t}$ ' test and Chi-square test and Logistic regression analysis were performed using SPSS Version 20. Data were expressed as mean and \pm SE \& in percentage. $p$ value $<0.05$ was taken as statistically significant level.

\section{Results}

The baseline characteristics of all subjects are presented in Table I. The mean value of age and weight were significantly $(\mathrm{P}<0.001)$ higher in diagnosed senile cataract group (DSC) than those of non cataract group (NCG).

In the present study, the mean BMI, WC, W: $\mathrm{H}$ were significantly $(\mathrm{p}<0.001)$ higher in DSC than those of NCG (Table II). Moreover, the mean TC, TG and LDL-c levels were significantly higher $(\mathrm{p}<0.001)$ and the mean HDL-c levels was significantly lower $(\mathrm{p}<0.001)$ in DSC than those of NCG (Table II). Again in this study, the subjects with higher BMI $\left(>25 \mathrm{~kg} / \mathrm{m}^{2}\right)$ were 4.64 times at a higher risk (95\% CI 2.889-7.440), the subjects with higher WC (>88 cm in female and $>102 \mathrm{~cm}$ in male) were 1.76 times at a higher risk $(95 \% \mathrm{CI}$ $1.3152 .344, \mathrm{p}<0.01)$ the subjects with higher $\mathrm{W}: \mathrm{H}(>0.85$ in female and $>0.9$ in male $)$ were 2.47 times at a higher risk ( $95 \% \mathrm{CI}: 1.8203 .353, \mathrm{p}<0.001)$ for developing cataract (Table III)

Table I: Baseline characteristics of the subjects in both groups $(n=200)$

\begin{tabular}{lcc}
\hline Parameters & NCG $(\mathrm{n}=100)$ & DSC $(\mathrm{n}=100)$ \\
\hline Age $($ years $)$ mean \pm SE & $51.75 \pm 7.50$ & $57.99 \pm 8.63^{* * *}$ \\
Male no. $(\%)$ & $58(58)$ & $54(54)$ \\
Female no. $(\%)$ & $42(42)$ & $46(46)$ \\
SBP $(\mathrm{mmHg})$ mean \pm SE & $120.90 \pm 14.64$ & $141.25 \pm 21.80^{* * *}$ \\
DBP $(\mathrm{mmHg})$ mean \pm SE & $78.30 \pm 10.57$ & $91.70 \pm 14.34^{* * *}$ \\
\hline
\end{tabular}

Results are expressed as mean $\pm \mathrm{SE}$. Data are analyzed by Chi square test and unpaired Student's ' $\mathrm{t}$ ' test. $\mathrm{SBP}=$ Systolic blood pressure, $\mathrm{DBP}=$ Diastolic blood pressure. ${ }^{* * *} \mathrm{p}<0.001$

$\mathrm{NCG}=$ noncataract group, $\mathrm{DSC}=$ diagnosed senile cataract group.

Table II: Body mass index(BMI), waist circumference(WC), waist hip circumference ratio (W:H), serum lipid \& lipoprotein levels in the subjects in both groups $(n=200)$

\begin{tabular}{lcc}
\hline Parameters & NCG $(\mathrm{n}=100)$ & DSC $(\mathrm{n}=100)$ \\
\hline BMI $\left(\mathrm{kg} / \mathrm{m}^{2}\right)$ & $23.97 \pm 0.33$ & $28.04 \pm 0.29^{* * *}$ \\
WC $(\mathrm{cm})$ & $85.37 \pm 0.93$ & $93.96 \pm 0.85^{* * *}$ \\
W: H & $0.83 \pm 0.007$ & $0.89 \pm 0.007^{* * *}$ \\
TC $(\mathrm{mg} / \mathrm{dl})$ & $156.56 \pm 3.95$ & $223.69 \pm 5.79^{* * *}$ \\
TAG $(\mathrm{mg} / \mathrm{dl})$ & $141.63 \pm 4.41$ & $210.40 \pm 8.17^{* * *}$ \\
HDL-C $(\mathrm{mg} / \mathrm{dl})$ & $44.66 \pm 1.05$ & $34.91 \pm 0.39^{* * *}$ \\
LDL-C $(\mathrm{mg} / \mathrm{dl})$ & $93.66 \pm 2.62$ & $147.30 \pm 5.49^{* * *}$ \\
\hline
\end{tabular}

Results are expressed as mean \pm SE. Data are analyzed by unpaired Student's 't' test.

$\mathrm{TC}=$ total cholesterol, $\mathrm{TAG}=$ Triacylglycerol, HDL-C $=$ High density lipoprotein cholesterol

LDL-C $=$ Low density lipoprptein cholesterol. $* * * p<0.001$

$\mathrm{NCG}=$ noncataract group, $\mathrm{DSC}=$ diagnosed senile cataract group.

J Bangladesh Soc Physiol. 2018, June; 13(1): 29-34 
Table III: Logistic regression analysis of risk factors for senile cataract in both groups $(n=200)$

\begin{tabular}{|c|c|c|c|c|c|c|}
\hline \multirow[t]{2}{*}{ Parameters } & \multicolumn{2}{|c|}{ NCG (100) } & \multicolumn{2}{|c|}{ DSC (100) } & \multirow[b]{2}{*}{ ODDS Ratio } & \multirow[b]{2}{*}{$95 \% \mathrm{CI}$} \\
\hline & No. & $\%$ & No. & $\%$ & & \\
\hline \multicolumn{7}{|c|}{$\mathrm{BMI}(\mathrm{Kg} / \mathrm{m} 2)$} \\
\hline$<25.0$ & 25 & $(25.0)$ & 85 & $(85.0)$ & 0.27 & $0.191-0.390$ \\
\hline$>25.0$ & 75 & $(75.0)$ & 15 & $(15.0)$ & 4.64 & $2.889-7.440 * * *$ \\
\hline \multicolumn{7}{|l|}{$\mathrm{WC}(\mathrm{cm})$} \\
\hline$<88 />102$ & 26 & $(26.0)$ & 67 & $(67.0)$ & 0.45 & $0.260-0.790$ \\
\hline$>88 /<102$ & 74 & $(74.0)$ & 33 & (33.0) & 1.76 & $1.315-2.344^{* *}$ \\
\hline \multicolumn{7}{|l|}{$\mathrm{W}: \mathrm{H}$} \\
\hline$<0.85 /<0.90$ & 22 & $(22.0)$ & 66 & $(66.0)$ & 0.36 & $0.245-0.526$ \\
\hline$>0.85 />0.90$ & 78 & $(78.0)$ & 34 & $(34.0)$ & 2.47 & $1.820-3.353 * * *$ \\
\hline \multicolumn{7}{|l|}{ TC(mg/dl) } \\
\hline$<200$ & 14 & $(14.0)$ & 71 & (71.0) & 0.22 & $0.135-0.360$ \\
\hline$>200$ & 86 & $(86.0)$ & 29 & $(29.0)$ & 3.31 & $2.385-4.601 * * *$ \\
\hline \multicolumn{7}{|l|}{ TAG(mg/dl) } \\
\hline$<160$ & 28 & $(28.0)$ & 79 & (79.0) & 0.34 & $0.241-0.413$ \\
\hline$>160$ & 72 & $(72.0)$ & 21 & (21.0) & 3.21 & $2.207-4.843 * * *$ \\
\hline \multicolumn{7}{|c|}{ HDL-c(mg/dl) } \\
\hline$<36$ & 21 & $(21.0)$ & 75 & (75.0) & 0.29 & $0.194-0.427$ \\
\hline$>36$ & 79 & $(79.0)$ & 25 & $(25.0)$ & 3.25 & $2.273-4.647 * * *$ \\
\hline \multicolumn{7}{|c|}{ LDL-c(mg/dl) } \\
\hline$<140$ & 7 & $(7.0)$ & 60 & $(60.0)$ & 0.15 & $0.073-0.304$ \\
\hline$>140$ & 93 & $(93.0)$ & 40 & $(40.0)$ & 2.98 & $2.269-3.907 * * *$ \\
\hline
\end{tabular}

Logistic regession analysis was performed to find out odds ratio.. $\mathrm{BMI}=$ body mass index, $\mathrm{WC}=$ waist circumference, $\mathrm{W}: \mathrm{H}=$ waist hip circumference ratio, $\mathrm{TC}=$ total cholesterol, $\mathrm{TAG}=$ triacylglycerol, HDL-C $=$ high density lipoprotein cholesterol LDL-C $=$ low density lipoprptein cholesterol. NCG v/s DSC $* * * p<0.001, * * p<0.01 . C I=$ Confidence interval, $\mathrm{O}=$ Odds ratio (risk ratio), NCG $=$ non cataract group, $\mathrm{DSC}=$ diagnosed senile cataract group. $\mathrm{N}=$ Number of subject

\section{Discussion}

In the present study, the mean BMI, mean WC and mean W:Hwas significantly higher in diagnosed senile cataract patients as compared to noncataract group which was similar to others ${ }^{11,19-20}$. Whereas few researchers found lower BMI and lower W:H in cataract patients ${ }^{21}$ Moreover the subjects with higher BMI, higher WC and higher W:H were at a high risk of developing cataract. Few studies also found significant association of obesity with senile cataract that was concordant with our findings 11,14 .

Again, in the present study, the mean TC, mean TAG, mean LDL level were higher and the mean HDL level was lower in diagnosed senile cataract patients in comparison to that of noncataract 
group which was in agreement with the study of many researchers of different countries ${ }^{5,13,21-23}$. On the other hand, some researchers did not found any significant change in TAG and HDL levels of cataract patients ${ }^{13}$.

Moreover in this study, the subjects with higher TC, higher TAG level, lower HDL-C level, higher LDL-C level were associated with developing cataract which was in agreement with many researchers ${ }^{5,13,21-23}$. But some other researchers did not found any association of lipid profile with the development of cataract ${ }^{19}$.

Obesity has been proposed to be a risk factor for cataract development, though the exact underlying mechanisms are unclear. Several pathophysiological mechanisms have been proposed to explain the association of obesity and cataract ${ }^{19}$. Some researcher suggested that leptin, a 16-kDa pleiotropic cytokine expressed and secreted mainly by adipocytes, is involved in the mechanisms underlying of cataract formation $^{24-25}$ Individuals with obesity exhibit hyperleptinemia and leptin resistance. Leptin has also been found to increase accumulation of reactive oxygenspeciies ${ }^{25}$. Recent studies have proposed that oxidative stress play an important pathogenic role in cataract formation by damaging the DNA membrane permeability system. Thus hyperleptinemia promotes cataract formation ${ }^{24,26}$.

The development of cataract is associated with some lipid changes in human lens fibers ${ }^{10}$.

Cholesterol representing approximately $40 \%$ of the total lipids of human lens fibers ${ }^{26}$. Any change of serum cholesterol level may alter optical lens properties. Cholesterol distribution in the lens appears to follow an unusual pattern, concentrating in the pericortical region. As an unsaturated lipoprotein, cholesterol is able to autoxidise. This autoxidation can be initiated by most of the reactive oxygen species ${ }^{13}$. As human lens exists continuously in a strong photoxidative environment, a chronic exposure to UV light, and ozone can lead to the formation of some cholesterol oxide derivatives (also named oxysterol) which accumulate in human cataractous lens ${ }^{10}$.

High concentration of cholesterol in lens membranes may provide the most important substrate for oxidation. Oxidation of cholesterol may be associated with cataract formation ${ }^{13}$.

Furthermore the high density lipoprotein (HDL) acts as an antioxidant. So it can protect the lens against oxidative damage. But in case of dyslipidemia there is no protection against the free radical damage to cellular DNA, lipids and proteins $^{13}$.

In the present study, obesity and dyslipidemia may act as risk factor as evidenced by measured higher BMI,WC,W:H,TC, TG, LDL-c and lower HDL-c levels in diagnosed senile cataract patients.

\section{Conclusion}

From the results of this study, it is concluded that obesity and dyslipidemia may act as risk factors for development of senile cataract.

\section{Acknowledgement}

The authors acknowledge Department of Ophthalmology and Department of Pathology of Dhaka Medical College, Dhaka for their cooperation during sample collection.

\section{Conflict of interest}

The authors declare no conflict of interest for this study

\section{Authors Affiliations}

1. *Sabrina Fahmida Azim, Assistant Professor, Department of Physiology, KumudiniWomens Medical College, Mirzapur, Tangail. Email: sabrinafahmida@yahoo.com

2. Qazi Shamima Akhter, Professor and Head, Department of Physiology, Dhaka Medical College, Dhaka. Email: shamimaqazi@yahoo.com

3. TaslimaAkter,Assistant Professor, Department of Physiology, Ibrahim Medical College, Dhaka. Email: taslimaakter783160@gmail.com

4. Fouzia Farid, Assistant Professor, Department of Physiology, Dhaka Community Medical College. Email:fouzia.shukty@gmail.com

*For correspondence 


\section{Refferences}

1. Sihota R, Tandon R. Parsons' Diseases o the eye. $20^{\text {th }}$ ed. New Delhi: Elsevier 2007; The lens; 248-51p.

2. WHO. Programmes [internet].Geneva: World Health Organization: c 2015. Priority eye disease $2010 \quad$ [cited $2014 \quad$ Oct 12].Availablefrom:www.who.int/ blindness/causes/ priority/en/index 1.html .

3. Kanagarajan P, Nandi P, Lokeshmaran A. Prevalence of cataract blindness in a rural puducherry. Indian Med Gaz 2011;348-52.

4. Dineen BP. Bourne RR, Ali SM, Huq DMN, Johnson GJ. Prevalence and causes of blindness and visual impairment in Bangladeshi adults: results of the national blindness and low vision survey of Bangladesh. Br J Ophthalmol 2003;87(7):820-28.

5. Heydari B, Kazemi T, Zarban A, Ghahramani S. Correlation of cataract with serum lipids, glucose and antioxidant activities: a case- control study. West Indian Med J 2012;61(3):230.

6. West S, Munoz B, Olive D. Cigarette smoking and risk for progression of nuclear opacities. Arch Ophthalmol 1995;113(11): 1377-80.

7. WHO. Media center:Fact sheet.[Internet] Geneva: World Health Oraganization:c2014.Obesity and overweight;2014[cited 2014 Nov10];Available from file:///E:/who_obesity and overweight.html

8. Misra A, Khurana L. Obesity-related noncommunicable diseases: South Asians vs White Caucasians. Intern J Obes 2011;35,167-87p.

9. Lim LS, Tai E, Aung T, Tay WT, Saw SM, Seislstad M, Wong TY. Relation of age related cataract with obesity and obesity genes in an Asian population. Am J Epidemol 2009;169(10):1267-74.

10. Vejux A, Samadi M, Lizard G. Contribution of cholesterol and oxysterols in the physiopathology of cataract: Implication for the development of pharmacological treatments. J ophthalmol 2011(2011):8

11. Paunksnis A, Bojarskiene F, Cimbalas A. Relation between cataract and metabolic syndrome and its componenets. Eur J Ophthalmol2007;17:60.

12. Hiller R, Sperduto RD, Reed GF, D' Augostino RB. Wilson PWF. Serum lipids and age-related lens opacities: a longitudinal investigation: the Framingham Studies. Ophthalmol2003;110:57883.

13. Meyer D, Parkin D, Maritz FJ, Liebenberg PH. Abnormal serum lipoprotein levels as a risk factor the development of human lenticular opacities. Cardiovasc J South Afr2003;14:60-4.
14. Sabanayagam C, Wang JJ, Mitchell P, TanAG,TaiES,Aung T, Saw SM,WongTY. Metabolic Syndrome Components and Age-Related Cataract: The Singapore Malay Eye Study.InvestOphthalmol Vis Sci 2011;52:23972404.

15. Durant JD, Frost NA, Trivella M, Sparrow JM . Risk factors for cataract subtypes waterclefts and retrodots: two case-control studies. Eye 2006;20:1254-67.

16. Hubbard VS. Defining overweight and obesity: what are the issues? Am J Clin Nutr2000;72:1067-8.

17. Levine ME \& Crimmins EM. The impact of insulin resistance and inflammation on the association between sarcopenic obesity and physical functioning. Obesity 2012;20:2101-6.

18. Deepa S, Shanthirani CS, Premalatha G, Sastry, Mohan V. Prevalence of insulin resistance syndrome in a selected south Indian population-The Chennai urban population study-7. Indian J Med Res 2002;115:118-27.

19. Cheung $\mathrm{N}$ and Wong, TY. Obesity and eye disease. Surv Ophthalmol 2007; 52(2): 180-95.

20. Foster PJ, Wong TY, Machin D, Johnson GJ, Seah SKL. Risk factors for nuclear, cortical and posterior subcapsular cataracts in the Chinese population of Singapore: The Tanjong Pagar Survey.Br J Ophthalmol 2003;87: 1112-20.

21. Rim TH, Kim M, Kim WC, Kim TI and Kim EK. Cataract subtype risk factors identified from the Korea national health and nutrition examination survey 2008-2010. BMC Ophthalmol 2014: 14(4):1-15.

22. Chandrasekar R, Dhanarajan MS, Lalitha PS, Srinivas M.Relationship between human agerelated cataracts and some serum routine biochemical parameters of Indian population. Int J Clin Bio chem Res 2014;1(1):10-15.

23. Raman R, Pal SS, Adams JS. Prevalence and risk factors for cataract in diabetes: SankaraNethralaya diabetic retinopathy epidemiology and molecular genetics study, report no. 17.Invest Ophthalmol Vis Sci 2010;51(12):6253-61.

24. Gomez-Ambrosi J, Salvador J, Fruhbeck G. Is hyperleptinemia involved in the development of age-related lens opacities? Am J Clin Nutr 2004; 79:888-9.

25. Garofalo C, Surmacz E. Leptin and cancer. J Cell Physiol. 2006;207:12-22

26. Bouloumie A, Marumo T, Lafontan M, Busse R. Leptin induces oxidative stress in human endothelial cells. FASEB J 1999;13:1231-8. 